\title{
Энергоэффективные газовые сенсоры на основе нанокристаллического оксида индия
}

\author{
(c) Е.А. Форш, Е.А. Гусева \\ Московский автомобильно-дорожный государственный технический университет, \\ 125319 Москва, Россия \\ E-mail: forsh_kate@list.ru
}

Поступила в Редакцию 16 мая 2019 г.

В окончательной редакции 2 октября 2019 г.

Принята к публикации 2 октября 2019 г.

\begin{abstract}
Исследовано влияние размера нанокристаллов на чувствительность нанокристаллического оксида индия $\mathrm{In}_{2} \mathrm{O}_{3}$ с чрезвычайно малым размером нанокристаллов (от 7 до $40 \mathrm{Hм}$ ), синтезированного золь-гель методом, к диоксиду азота в низких концентрациях при комнатной температуре при ультрафиолетовом освещении и без освещения. Обнаружено, что наибольший отклик к диоксиду азота демонстрирует образец с промежуточным размером нанокристаллов. Продемонстрирована возможность использования нанокристаллического $\mathrm{In}_{2} \mathrm{O}_{3}$ при создании сенсора для детектирования $\mathrm{NO}_{2}$ в воздухе при комнатной температуре в условиях дополнительной УФ подсветки. Показано, что такой сенсор может работать и в условиях импульсной подсветки, что позволит существенно понизить его энергопотребление.
\end{abstract}

Ключевые слова: нанокристаллический оксид индия, ультрафиолетовое освещение, проводимость, фотопроводимость, диоксид азота.

DOI: 10.21883/FTP.2020.02.48912.9159

\section{1. Введение}

Контроль загрязнений окружающей среды является одной из важнейших актуальных задач. Для решения этой задачи используют газовые сенсоры, одним из типов которых являются газовые сенсоры резистивного типа. Резистивные газовые сенсоры обладают рядом преимуществ по сравнению с оптическими, электрохимическими и спектроскопическими сенсорными системами, поскольку они дешевые в изготовлении, компактные и простые в использовании. Однако одним из недостатков резистивных сенсоров является то, что для обеспечения их работы чувствительный элемент сенсора должен быть нагрет до высокой температуры (обычно 400-500 $\mathrm{C}$ ). Это условие приводит к сравнительно большому энергопотреблению сенсора, основная часть которого идет на питание нагревательного элемента. Кроме того, сенсоры, работающие при такой высокой температуре, могут стать причиной возгорания во взрывоопасных средах. Таким образом, снижение рабочей температуры чувствительного элемента позволило бы повысить энергоэффективность резистивных газовых сенсоров и расширить сферы их применения. Для снижения рабочей температуры резистивных газовых сенсоров возможно использовать дополнительную подсветку вместо нагрева. При этом в результате взаимодействия с газом регистрируется уже изменение не темновой проводимости, а фотопроводимости.

Одним из перспективных материалов для резистивных газовых сенсоров является нанокристаллический оксид индия $\left(\mathrm{In}_{2} \mathrm{O}_{3}\right)$ [1-7]. Нанокристаллический оксид индия в общем случае представляет собой пористую структуру, состоящую из кристаллитов нанометрового разме- pa $[8,9]$. Такой нанокристаллический $\operatorname{In}_{2} \mathrm{O}_{3}$ используют в качестве активного слоя газового сенсора на газы-окислители, в частности диоксид азота $\left(\mathrm{NO}_{2}\right)$ [9-13]. Диоксид азота - один из самых распространенных загрязнителей атмосферного воздуха, выделяющийся с выхлопными газами двигателей внутреннего сгорания. Всемирная организация здравоохранения внесла этот газ в перечень приоритетных загрязнителей воздуха.

При изменении состава окружающей среды изменяется как темновая, так и фотопроводимость оксидов металлов. При комнатной температуре стационарная фотопроводимость может сильно изменяться в присутствии газов-окислителей, таких как диоксид азота.

Фотопроводимость, в отличие от темновой проводимости [14], сильно зависит от процессов рекомбинации и генерации носителей заряда. В связи с чем изменение проводимости нанокристаллического оксида индия при взаимодействии с детектируемым газом в условиях освещения может определяться процессами генерации и рекомбинации неравновесных носителей заряда. Однако до сих пор влияние адсорбции на данные процессы в нанокристаллическом оксиде индия не было изучено. В имеющихся немногочисленных статьях, посвященных изучению чувствительности нанокристаллических оксидов металлов к детектируемым газам при освещении, процессы генерации и рекомбинации носителей заряда не рассматривались. В то же время исследования фотоэлектрических свойств нанокристаллического оксида индия с различной структурой позволят связать структурные параметры с процессами генерации и рекомбинации носителей заряда и, следовательно, установить оптимальные параметры для использования нанокристаллического оксида индия в газовых сенсорах. В данной 
Таблица 1. Предельно допустимые концентрации $\mathrm{NO}_{2}$ в воздухе

\begin{tabular}{c|c|c|c|c|c}
\hline \multicolumn{2}{c|}{$\begin{array}{c}\text { ПДК } \\
\text { рабочей зоны }\end{array}$} & \multicolumn{2}{c|}{$\begin{array}{c}\text { ПДК } \\
\text { максимальная разовая }\end{array}$} & \multicolumn{2}{c}{$\begin{array}{c}\text { ПДК } \\
\text { среднесуточная }\end{array}$} \\
\hline $\mathrm{M \Gamma} / \mathrm{M}^{3}$ & $\mathrm{ppm}$ & $\mathrm{M \Gamma} / \mathrm{M}^{3}$ & $\mathrm{ppm}$ & $\mathrm{M \Gamma} / \mathrm{M}^{3}$ & $\mathrm{ppm}$ \\
\hline 2 & 1 & 0.2 & 0.1 & 0.04 & 0.02
\end{tabular}

работе проведены комплексные исследования влияния газа-окислителя на стационарную и нестационарную фотопроводимость при разных спектральных характеристиках и режимах освещения нанокристаллического оксида индия с различным размером нанокристаллов, площадью удельной поверхности, а также модифицированного нанокристаллического оксида индия.

\section{2. Исследованные образцы и методика измерений}

Для коммерческих сенсоров важно детектировать концентрации диоксида азота в районе нескольких ррm и даже сотен $\mathrm{ppb}$, так как уже в таких концентрациях диоксид азота оказывает вредное влияние на организм человека. Предельно допустимые концентрации (ПДК) $\mathrm{NO}_{2}$ в воздухе представлены в табл. 1.

Для обеспечения чувствительности к таким низким концентрациям диоксида азота нанокристаллический оксид индия должен иметь очень развитую поверхность и состоять из кристаллитов как можно меньшего размера. Поэтому в работе был синтезирован нанокристаллический оксид индия с очень большой удельной поверхностью и нанокристаллами размером от единиц до нескольких десятков нанометров.

Нанокристаллические образцы оксида индия были изготовлены золь-гель методом с последующим отжигом при различных температурах $\left(T=300-700^{\circ} \mathrm{C}\right)$ в течение 24 ч (синтез образцов подробно описан в рабо$\operatorname{Tax}[15,16])$.

Структурные особенности исследуемых образцов (фазовый состав, степень дисперсности, размер нанокристаллов) изучались с помощью рентгеновской дифракции и просвечивающей электронной микроскопии. Площадь удельной поверхности образцов оценивали ме- тодом низкотемпературной адсорбции азота, расчеты проводили по модели Брунауэра-Эммета-Теллера [17].

Анализ данных рентгеновской дифракции и просвечивающей электронной микроскопии образцов, отожженных при различных температурах, показал, что все образцы характеризуются кубической модификацией кристаллического оксида индия. При этом размеры нанокристаллов тем больше, чем выше температура отжига образца. Обозначения образцов и их структурные параметры указаны в табл. 2.

Для исследований фотоэлектрических характеристик на верхнюю поверхность пленок с помощью вакуумного универсального поста ВУП-5 напылялись золотые контакты, расстояние между которыми равнялось 0.5 мм. Затем образцы помещались в азотный криостат, позволяющий проводить измерения как при атмосферном давлении, так и при вакууме. Образец освещали с помощью УФ светодиода с длиной волны 380 нм. Интенсивность падающего на образец света при этом равнялась $5 \mathrm{mBT} / \mathrm{cm}^{2}$. Фототок, возникающий в образце в результате поглощения в нем света, регистрировался пикоамперметром Keithley 6487.

Для исследования влияния адсорбции диоксида азота азотный криостат с помещенным в него образцом продувался сухим воздухом с необходимой для измерения концентрацией $\mathrm{NO}_{2}$. Концентрация в экспериментах менялась от 2 до $8 \mathrm{ppm}$.

\section{3. Основные результаты и выводы}

Ранее нами были изучены оптические свойства, а также исследованы спектральная зависимость фотопроводимости и кинетики нарастания и спада фотопроводимости исследуемых образцов [16]. Исследования спектральной зависимости фотопроводимости показали, что максимум фотопроводимости соответствует энергии квантов $3.2-3.3$ эВ. Именно по этой причине для исследования влияния адсорбции диоксида азота на фотоэлектрические свойства нанокристаллического оксида индия нами был выбран УФ диод с длиной волны 380 нм (энергией квантов 3.25 эВ).

Наши предыдущие исследования показали, что наибольший отклик на присутствие в атмосфере диоксида азота показал образец с промежуточным размером нанокристаллов [18], наши дальнейшие исследования были проведены именно для этого образца. В атмосфере диоксида азота темновая проводимость и фотопроводимость

Таблица 2. Обозначения образцов и их структурные параметры

\begin{tabular}{c|c|c|c}
\hline Образец & $\begin{array}{c}\text { Температура } \\
\text { отжига, }{ }^{\circ} \mathrm{C}\end{array}$ & $\begin{array}{c}\text { Средний размер } \\
\text { нанокристаллов, нм }\end{array}$ & $\begin{array}{c}\text { Площадь удельной } \\
\text { поверхности, } \mathrm{M}^{2} / \Gamma\end{array}$ \\
\hline $\mathrm{In}_{2} \mathrm{O}_{3}-300$ & 300 & 7 & 100 \\
$\mathrm{In}_{2} \mathrm{O}_{3}-500$ & 500 & 20 & 35 \\
$\mathrm{In}_{2} \mathrm{O}_{3}-700$ & 700 & 40 & 10
\end{tabular}




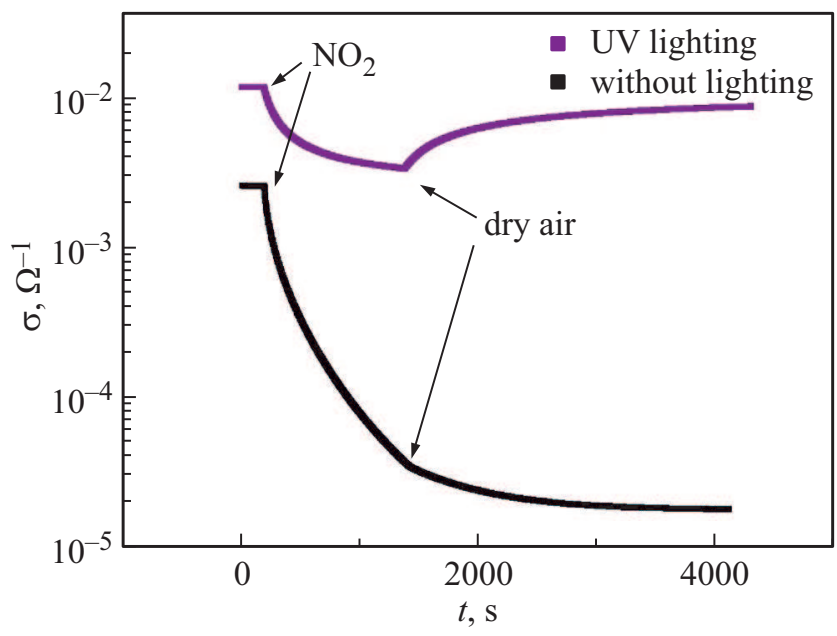

Рис. 1. Изменение темновой проводимости и фотопроводимости образца нанокристаллического оксида индия со средним размером нанокристаллов 20 нм при напуске диоксида азота и последующем продуве сухим воздухом.
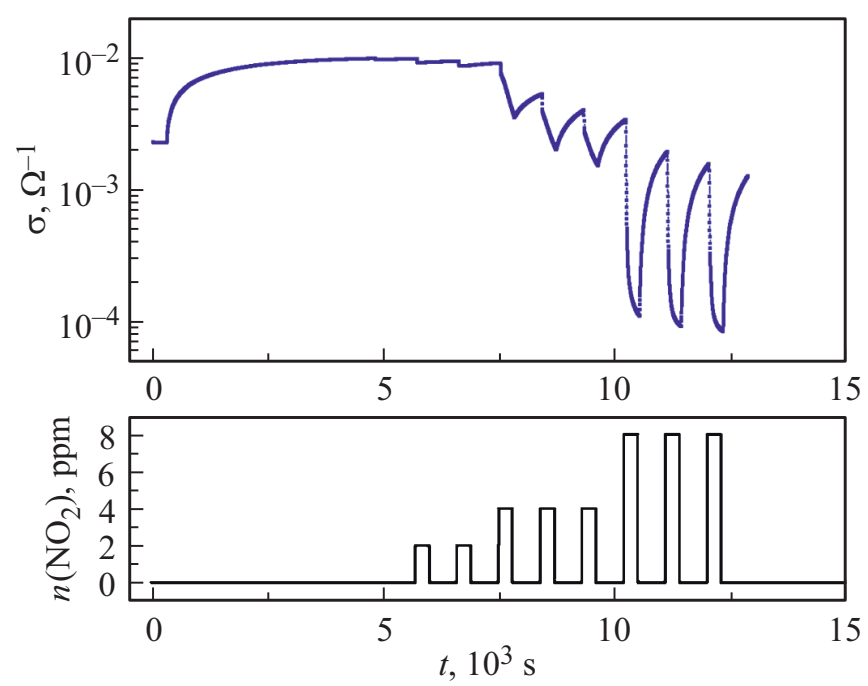

Рис. 2. Кинетика изменения проводимости в условиях освещения при периодическом напуске диоксида азота в разных концентрациях (верхняя часть рисунка). Концентрация диоксида азота в воздухе на протяжении эксперимента отображена на нижней части рисунка.

нанокристаллического оксида индия уменьшаются. На рис. 1 показано изменение при комнатной температуре темновой проводимости и фотопроводимости нанокристаллического оксида индия при напуске диоксида азота (на примере образца со средним размером нанокристаллов 20 нм). После напуска диоксида азота образец помещался в атмосферу сухого воздуха без диоксида азота. Как можно видеть, темновая проводимость нанокристаллического оксида индия сильно уменьшается в атмосфере диоксида азота. Причем изменение темновой проводимости в атмосфере диоксида азота необратимое, так как темновая проводимость не возвращается к свое- му первоначальному значению после удаления диоксида азота из атмосферы.

Фотопроводимость нанокристаллического оксида индия в атмосфере диоксида азота также уменьшается. Однако, в отличие от темновой проводимости, изменения фотопроводимости обратимы. Из рис. 1 видно, что при удалении диоксида азота из атмосферы фотопроводимость восстанавливается практически до своего первоначального значения.

На рис. 2 показана кинетика изменения фотопроводимости нанокристаллического оксида индия со средним размером нанокристаллов 20 нм при периодическом напуске диоксида азота в воздушную среду в разных концентрациях. В момент времени $t=5$ мин было включено освещение ультрафиолетовым светом. Через час после освещения фотопроводимость увеличилась на порядок и достигла стационарного значения. С момента выхода фотопроводимости на стационарное значение на образец напускалась смесь сухого воздуха с диоксидом азота в разных концентрациях. Из рис. 2 видно, что величина изменения проводимости при освещении зависит от концентрации диоксида азота в воздухе. Исследования показали, что наибольшей чувствительностью к диоксиду азота при освещении обладает образец $\operatorname{In}_{2} \mathrm{O}_{3}$ со средним размером нанокристаллов 20 нм.

Была изучена возможность использования нанокристаллического $\mathrm{In}_{2} \mathrm{O}_{3}$ в качестве датчика, освещенного модулированным ультрафиолетовым светом (см. рис. 3).

Уменьшение рабочего времени светодиодов приводит к эффективному снижению энергопотребления датчика. В экспериментах с мигающим УФ светом светодиод работал в периодическом режиме с периодом $15 \mathrm{c}$. Наблюдалось два режима работы: при включении светодиода на 4 с („,режим 1“) и на 1 с (,,режим 2“) (рис. 3,a). Изменения проводимости становятся незначительными и достигают стационарного состояния через 2 ч после включения модулированного освещения. С этого момента увеличение проводимости при освещении было равно ее уменьшению при выключенном светодиоде. Можно заметить, что для обоих режимов освещения фотопроводимость устанавливается практически на одно и то же значение. Для определения сигнала датчика образец $\mathrm{In}_{2} \mathrm{O}_{3}-500$ подвергали воздействию 8 ppm $\mathrm{NO}_{2}$ в течение $30 \mathrm{c}$, а затем образец подвергали воздействию сухого воздуха в течение 30 мин. Для оценки стабильности и воспроизводимости эту процедуру повторяли несколько раз. Результаты указывают на возможность использования модулированного освещения для обнаружения диоксида азота при комнатной температуре.

Оценим теперь приблизительный расход энергии УФ светодиода, излучающего на длине волны 385 нм. Такой светодиод имеет среднюю эффективность 15\% [19]. В таком случае потребление энергии для освещения образцов (расстояние между контактами 0.3 мм, длина контакта -3 мм) будет меньше 1 мВт при непрерывном освещении, если использовать мигающий режим, то энергозатратность будет еще меньше. 

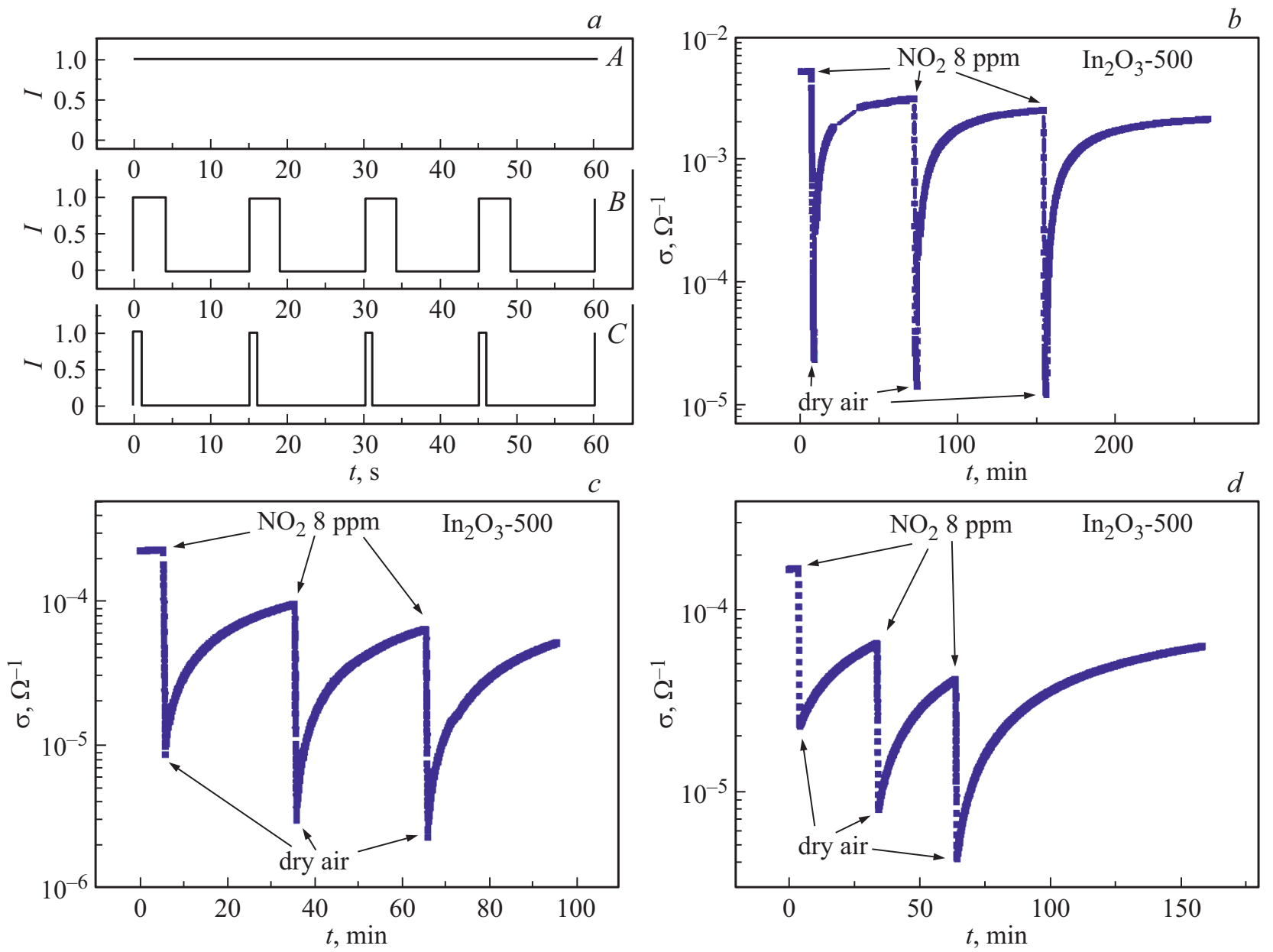

Рис. 3. $а$ : режимы работы УФ светодиода $A)$ - непрерывная работа, $B)$ - режим 1 - модулированное освещение с периодом 15 с, из которых светодиод горит 4 с. $B$ ) - режим 2 - модулированное освещение с периодом 15 с, из которых светодиод горит $1 \mathrm{c})$. $b$ : электропроводность образца $\operatorname{In}_{2} \mathrm{O}_{3}-500$ при комнатной температуре при непрерывном освещении (режим $A$ ) и 8 ppm $\mathrm{NO}_{2}$ в сухом воздухе. $c$ : электропроводность образца $\operatorname{In}_{2} \mathrm{O}_{3}-500$ при комнатной температуре при импульсном освещении (режим $B$ ) и $8 \mathrm{ppm} \mathrm{NO}_{2}$ в сухом воздухе. $d$ : электропроводность образца $\mathrm{In}_{2} \mathrm{O}_{3}-500$ при комнатной температуре при импульскном освещении (режим $B$ ) и 8 ppm $\mathrm{NO}_{2}$ в сухом воздухе. Моменты воздействия $\mathrm{NO}_{2}$ отмечены стрелками.

Существующие на данный момент сенсоры на диоксид азота детектируют данный газ начиная с 1 ppm, однако максимальная разовая предельно допустимая концентрация (ПДК) данного газа для рабочей зоны равна 1 ppm, а для населенных пунктов - $500 \mathrm{ppb}$, среднесуточная ПДК для населенных пунктов равна 200 ppb. Таким образом, существующие сенсоры вполне подходят для использования на производствах (хотя было бы предпочтительней детектировать диоксид азота и в меньших концентрациях), но для бытового использования нет (отметим, что для бытового использования эти сенсоры также не подходят, поскольку требуют нагрева до высоких температур). Следовательно, необходимо создать сенсор, который будет детектировать диоксид азота начиная, как минимум, с 200 ppb. Для определения наименьшей чувствительности нанокристаллического оксида индия к диоксиду азота (при детектировании в условиях дополнительной оптической подсветки)

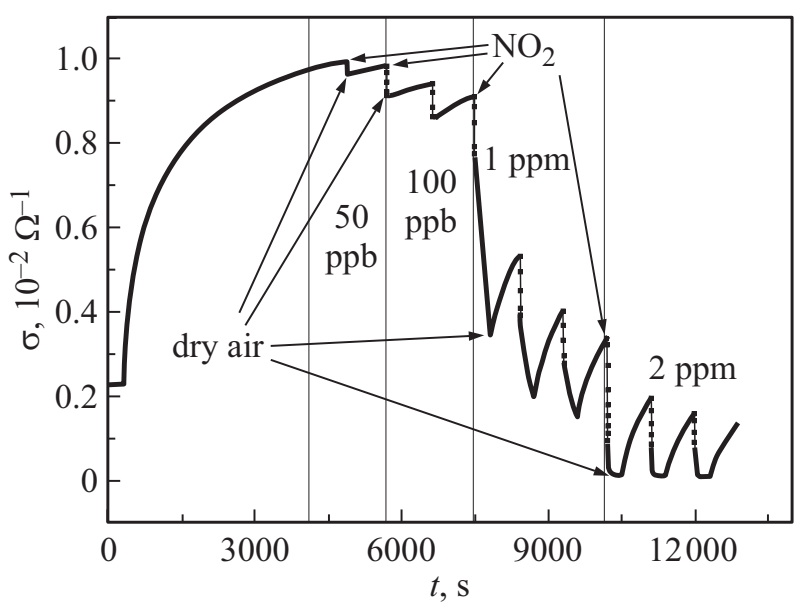

Рис. 4. Временна́я зависимость проводимости образца $\mathrm{In}_{2} \mathrm{O}_{3}-500$ при изменениях концентрации диоксида азота. 
были проведены дополнительные исследования изменения проводимости нанокристаллического оксида индия при адсорбции диоксида азота (см. рис. 4). Изменение проводимости нанокристаллического оксида индия зарегистрировано уже начиная с концентрации диоксида азота $50 \mathrm{ppb}$ (проводимость при этом изменилась на полпорядка для образца $\left.\mathrm{In}_{2} \mathrm{O}_{3}-500\right)$.

\section{4. Заключение}

Таким образом, установлено, что фотопроводимость нанокристаллического оксида индия уменьшается при адсорбции молекул $\mathrm{NO}_{2}$. Показано, что эффект изменения фотопроводимости нанокристаллического $\mathrm{In}_{2} \mathrm{O}_{3}$ при адсорбции $\mathrm{NO}_{2}$ обратим и может быть использован для создания газовых сенсоров, работающих при комнатной температуре в условиях подсветки. Кроме того, продемонстрирована возможность использования импульсной подсветки, что значительно уменьшает энергозатратность сенсоров на основе нанокристаллического оксида индия. При этом данный сенсор обладает следующими параметрами:

- диапазон определяемых концентраций $\mathrm{NO}_{2}$ 0.05-20 ppm;

- рабочая температура сенсора $-25-50^{\circ} \mathrm{C}$;

- время отклика материала в условиях светового облучения при комнатной температуре - не более 30 c;

- время релаксации сенсорного сигнала материала в условиях светового облучения при комнатной температуре - не более $30 \mathrm{c}$;

- время полного восстановления сенсора в условиях светового облучения при комнатной температуре - не более 30 мин;

— энергозатратность не превышает 1 мВт.

\section{Финансирование работы}

Работа проведена в рамках тематик, разрабатываемых в Московском автомобильно-дорожном государственном техническом университете.

\section{Конфликт интересов}

Авторы заявляют, что у них нет конфликта интересов.

\section{Список литературы}

[1] M. Epifani, R. Díaz, J. Arbiol, E. Comini, N. Sergent, T. Pagnier, P. Siciliano, G. Faglia, J.R. Morante. Sensors Actuators B, 126, 163 (2007).

[2] M.Z. Atashbar, B. Gong, H.T. Sun, W. Wlodarski, R. Lamb. Thin Sol. Films, 354, 222 (1999).

[3] C. Cantalini, W. Wlodarski, H.T. Sun, M.Z. Atashbar, M. Passacantando, S. Santucci. Sensors Actuators B: Chem., 65, $101(2000)$

[4] J. Chandradass, D.S. Bae, K.H. Kim. Adv. Powder Technol., 22, 370 (2011)
[5] H.M. Zahirul Alam, P.K. Saha, T. Hata, K. Sasaki. Thin Sol. Films, 352, 133 (1999).

[6] M. Suchea, N. Katsarakis, S. Christoulakis, S. Nikolopoulou, G. Kiriakidis. Sensors Actuators B: Chem., 118, 135 (2006).

[7] Su Kong Chong, Siti Nur Azieani Azizan, Kee Wah Chan, Hong-Quan Nguyen, Wee Siong Chiu, Zarina Aspanut, Chang Fu Dee, Saadah Abdul Rahman. Nanoscale Res. Lett., 8, 428 (2013).

[8] M.A. Flores-Mendoza, R. Castanedo-Perez, G. Torres-Delgado, J. Márquez Marín, O. Zelaya-Angel. Thin Sol. Films, 517, 681 (2008).

[9] M. Epifani, E. Comini, J. Arbiol, E. Pellicer, P. Siciliano, G. Faglia, J.R. Morante. J. Phys. Chem. C, 111, 13967 (2007).

[10] Salvador A. Palomares-Sancheza, Bernard E. Watts, Detlef Klimm, Andrea Baraldi, Antonella Parisini, Salvatore Vantaggio, Roberto Fornari. Thin Sol. Films, 645, 383 (2018).

[11] Haiming Cao, Pengfei Xing, Dongsheng Yao, Ping Wu. J. Magn. Magn. Mater., 429, 69 (2017).

[12] E.A. Forsh, V.B. Zaytsev, M.N. Martyshov, P.A. Forsh, P.K. Kashkarov. J. Nanoelectron. Optoelectron., 9, 762 (2014).

[13] A. Ilin, E. Forsh, N. Fantina, M. Martyshov, P. Forsh, P. Kashkarov. J. Nanoelectron. Optoelectron., 10, 680 (2015).

[14] E.A. Forsh, A.M. Abakumov, V.B. Zaytsev, E.A. Konstantinova, P.A. Forsh, M.N. Rumyantseva, A.M. Gaskov, P.K. Kashkarov. Thin Sol. Films, 595, 25 (2015).

[15] E.A. Forsh, A.V. Marikutsa, M.N. Martyshov, P.A. Forsh, M.N. Rumyantseva, A.M. Gaskov, P.K. Kashkarov. Thin Sol. Films, 558, 320 (2014)

[16] Е.А. Форш, П.А. Форш, П.К. Кашкаров. ФТП, 49, 1184 (2015).

[17] S. Brunauer. The adsorption of gases and vapors (Princeton,University Press Princeton, 1943).

[18] Е.А. Форш, А.В. Марикуца, М.Н. Мартышов, П.А. Форш, М.Н. Румянцева, А.М. Гаськов, П.К. Кашкаров. Росс. нанотехнологии, 7, 87 (2012).

[19] R. Karlicek. Ching-Cherng Sun, G. Zissis. Ruiqing Ma. Handbook of Advanced Lighting Technoligy (Springer, 2017) v. 1.

Редактор Г.А. Оганесян

\section{Energy efficient gas sensors based on nanocrystalline indium oxide}

\author{
E.A. Forsh, E.A. Guseva
}

\section{Moscow Automobile and Road Construction State Technical University, 125319 Moscow, Russia}

\begin{abstract}
The influence of grain size on the sensitivity of indium oxide with extremely small grains in range of $7-40 \mathrm{~nm}$ to nitrogen dioxide in low concentration at room temperature is investigated under the UV illumination. It is found that the sample with the intermediate size of nanocrystals shows the greatest response to nitrogen dioxide. The possibility of using nanocrystalline $\mathrm{In}_{2} \mathrm{O}_{3}$ to create a sensor for detecting $\mathrm{NO}_{2}$ in air at room temperature under UV illumination is demonstrated. It is shown that pulsed illumination may be used for $\mathrm{NO}_{2}$ detection at room temperature that significantly reduces the sensor power consumption.
\end{abstract}

